\title{
JuVentude e Gestão Social: um Relato das PRÁticas desenvolvidas pelo Projeto Gestão Social nas Escolas na Cidade de Juazeiro do Norte (CE)
}

\author{
Youth and Social Management: an account of the practices \\ developed by Gestão Social in schools in the city of Juazeiro do
}

Norte (CE)

\begin{abstract}
Waléria Maria Menezes Morais de Alencar
Psicóloga. Mestre em Gestão de Políticas Públicas. Professora assistente da Universidade Federal do Cariri. Coordenadora do Laboratório Interdisciplinar de Estudos em Gestão Social (LIEGS) e do Projeto Gestão Social nas Escolas. Juazeiro do Norte, CE, Brasil.E-mail: waléria.menezes@cariri.ufc.br
\end{abstract}

\section{Cícera Mônica da Silva Sousa Martins}

Psicóloga. Especialista em Políticas Públicas em Saúde Coletiva. Bolsista CNPq no Laboratório Interdisciplinar de Estudos em Gestão Social. Juazeiro do Norte, CE, Brasil. (LIEGS).E-mail: monicamartins_sousa@hotmail.com

\section{Ariela Karani da Silva}

Cientista Social. Especialista em Gestão de Projetos. Bolsista CNPq no Laboratório Interdisciplinar de Estudos em Gestão Social (LIEGS). São Paulo, SP, Brasil. E-mail: ariela.karani@gmail.com

\section{Resumo}

O Projeto Gestão Social nas Escolas é uma iniciativa do Laboratório Interdisciplinar de Estudos em Gestão Social (LIEGS) da Universidade Federal do Cariri (UFCA), cujo objetivo é fomentar, nos espaços escolares, práticas que estimulem o senso de coletividade e a participação social. A finalidade deste estudo é demonstrar como é possível contemplar os aportes teóricos da Gestão Social nas práticas pedagógicas. Esse projeto entrou em vigência em 2011 e perdura até os dias de hoje, tendo como público-alvo jovens de duas escolas públicas de ensino médio da cidade de Juazeiro do Norte. O presente trabalho consiste no relato das práticas ali realizadas e dos resultados percebidos no processo. Foi possível observar que, apesar das resistências iniciais, os jovens participaram de forma ativa do processo $e$ conseguiram desenvolver aspectos importantes em suas vidas, como a autonomia, a noção de pertencimento territorial $e$ a cooperação.

Palavras-chave: Gestão Social. Juventude. Participação Social. Juazeiro do Norte.

\section{Abstract}

The Projeto Gestão Social nas Escolas (PGSE) is an initiative of the Laboratório Interdisciplinar de Estudos em Gestão Social (LIEGS) of the Universidade Federal do Cariri (UFCA), which aims to promote the school spaces and practices that encourage a sense of community and social participation. The goal of this study is to demonstrate how you can combine the theoretical contributions of Social Management in pedagogical practices. This project came into force in 2011 and has survived to this day. Your target audience is young people from two public high schools of Juazeiro do Norte. This paper is a report of practices and results realized in the process. It was observed that despite initial resistance, the young people participated actively in the process and have developed important aspects in their lives, such as autonomy, territorial belonging and cooperation.

Keyword: Social management. Youth. Social participation. Juazeiro do Norte. 


\section{INTRODUÇÃo}

O contexto histórico brasileiro demonstra condições estruturais autoritárias, próprias do processo colonial, sendo reeditadas nas formas posteriores de governo, haja vista as ditaduras vivenciadas nas décadas de 1930 e 1970. Durante o Estado Novo, situado entre os anos de 1937 a 1945, imperava um modelo conservador, pautado no avanço da industrialização e na centralização do poder, pelas mãos do estadista Getúlio Vargas. Segundo Pacheco (2010), nesse período, ideias que fugiam a esse modelo eram vistas como práticas subversivas, passiveis de severas punições. O regime ditatorial militar, instaurado após o golpe de 1964, também utilizou de diversas técnicas de represália aos que manifestavam oposição ao modelo instaurado. Nesse contexto, desenvolvia-se uma cultura caracterizada pelo silêncio, ensinada por grupos que orquestram os padrões de dominação.

O principal dispositivo das relações de dominação é o poder, que funciona como uma prática de dominação sem local exclusivo, mas que se dissemina em toda a estrutura social. É possível observá-lo, portanto, nas diversas esferas sociais. Sendo assim, assume formas locais de manifestação, impregnando o nosso cotidiano e atingindo diretamente a vida das pessoas. Pode ou não ser vinculado ao Estado e sua função social é controlar e reprimir grupos com finalidade específica, qual seja: disciplinar corpos, tornando-os dóceis. Entende-se por corpos dóceis pessoas que foram ensinadas a agir de forma submissa ao padrão dominante (FOUCAULT, 1982).

Um local representativo nesse processo de controle é a escola, que, através da educação tradicional, dissemina a cultura do silêncio. A fundamentação desse modelo educacional está na dominação da consciência dos sujeitos, a partir da fala manipulativa que os disciplina e domestica, tornando-os passivos perante a construção de sua própria história.

Em contraponto ao modelo supracitado, a proposta de educação elaborada por Paulo Freire (2005b) tem como alvo principal a emancipação. Esta só ocorre no terreno da intercomunicação: "Ninguém educa ninguém, ninguém educa a si mesmo, os homens se educam entre si, mediatizados pelo mundo." (FREIRE, 2005b, p. 78).
Acredita-se que, como é possível - por meio da aprendizagem - fomentar uma subjetividade passiva, individualizada, é possível também aprender novos referenciais, voltados para o bem comum. Para isso acontecer, é preciso um posicionamento ético, capaz de romper com os jogos de poder, apontando, enfim, para uma estética da existência definida como prática emancipatória.

Partindo desses pressupostos, foi criado o Projeto Gestão Social nas Escolas, que tem como objetivo desenvolver a autonomia e participação, elementos propulsores para o desenvolvimento do protagonismo juvenil. Suas atividades ocorreram em escolas de ensino médio da rede pública da cidade de Juazeiro do Norte, no estado do Ceará. Para criar as ações do projeto, utilizamos como aporte teórico os preceitos da Gestão Social, que é definida como:

[...] processo gerencial dialógico onde a autoridade decisória é compartilhada entre os participantes da ação (ação que possa ocorrer em qualquer tipo de sistema social - público, privado ou de organizações não governamentais), voltada principalmente para ações empreendidas pela sociedade civil ou pelas políticas públicas sociais, em que os grupos cooperativados e organizados são o foco. (TENÓRIO, 2008, p. 40)

Essa nova racionalidade acerca da gestão pressupõe que os sujeitos envolvidos conduzam os processos de forma horizontal, com ênfase no entendimento mútuo e na negociação de conflitos. Nessa direção, este estudo objetiva refletir sobre como as ações da proposta supracitada contribuíram para a vivência dos princípios da gestão social nas escolas estaduais de Juazeiro do Norte.

O Projeto Gestão Social nas Escolas (PGSE) é uma iniciativa da Universidade Federal do Cariri (UFCA) realizada pelo Laboratório Interdisciplinar de Estudos em Gestão Social (LIEGS), com o apoio da Incubadora Tecnológica de Empreendimentos Populares e Solidários (ITEPS). O projeto conta com a parceria da $19^{a}$ Coordenadoria Regional de Desenvolvimento da Educação (CREDE 19-Juazeiro do Norte) da Secretaria da Educação do Governo do Estado do Ceará (SEDUC-CE) e da UNESCO. Obteve financiamento do Banco do Nordeste e do Programa de Apoio à Extensão Universitária do Ministério da Educação 
(PROEXT/MEC), atendendo duas escolas públicas de ensino médio de Juazeiro do Norte-CE.

Desde o início de 2011, o projeto vem realizando suas atividades no ambiente escolar com o objetivo promover o protagonismo dos jovens envolvidos e das comunidades alcançadas. A metodologia desenvolvida tem caráter participativo e busca ser um instrumento para desenvolver a autonomia $e$ a participação dos alunos. É esperado que, ao final do processo, as habilidades desenvolvidas durante o projeto ultrapassem os muros da escola, fazendo com que os jovens atuem como protagonistas também na solução dos problemas encontrados em sua comunidade.

\section{Contextualização do Território}

A região Nordeste do Brasil, onde acontece o projeto, possui uma extensão territorial de 1.558 .196 $\mathrm{km}^{2}$, onde, segundo o IBGE (2012), residem 53,59 milhões de pessoas. Entre os Estados que compõem essa região, está o Ceará, que, segundo o Instituto de Pesquisa e Estratégia Econômica do Ceará (2012), possui área total de $148.825,6 \mathrm{~km}^{2}$ e população aproximada de 8.671.086 pessoas. Esse Estado compreende 184 municípios e 20 Microrregiões Administrativas, dentre elas a Região Metropolitana do Cariri.

Entre as cidades pertencentes à Microrregião supracitada, encontra-se Juazeiro do Norte, com área de $248,55 \mathrm{~km}^{2}$ e população aproximada de 249.939 pessoas, sendo a cidade com maior densidade demográfica da região (IPECE, 2013). Experimenta, atualmente, um vigoroso processo de crescimento econômico, oriundo principalmente de atividades ligadas ao comércio e serviços, ao turismo religioso e à indústria calçadista. Paralelamente, essa localidade também enfrenta o crescimento vertiginoso da violência urbana e o aumento da quantidade de pessoas em situação de vulnerabilidade social, principalmente nos bairros periféricos.

No que se diz respeito à área da educação, Juazeiro do Norte possui atualmente, segundo o IBGE (2012), 309 escolas. Dentre essas escolas, 27 são de Ensino Médio. Foram contempladas com o projeto duas escolas situadas em bairros periféricos da cidade: o Centro de Apoio Integral à Criança e ao Adolescente Dom Antônio Campelo de Aragão (CAIC) e a Escola
Estadual Antônio Conserva Feitosa. A primeira está situada no bairro Frei Damião, criado recentemente, em decorrência de movimentos sociais liderados pelos moradores, que exigiam o seu reconhecimento na cidade. É perceptível, nessa localidade, o alto nível de violência e consumo de drogas, como também a predominância de famílias em situação de vulnerabilidade social. A segunda escola localiza-se no bairro Antônio Vieira, um bairro bastante populoso e com uma crescente presença de casos relacionados ao tráfico de entorpecentes e à criminalidade.

Os atores envolvidos foram os alunos do primeiro ano do ensino médio, que tinham idades entre 14 e 18 anos. A escolha dessa faixa etária justifica-se pelo caráter contínuo das ações, realizadas semanalmente, iniciadas no primeiro ano do ensino médio e continuadas até a conclusão do curso. O objetivo inicial do projeto foi estimular o desenvolvimento do protagonismo juvenil partindo das potencialidades já existentes nos alunos e, paralelamente a isso, trabalhar aspectos relacionados à comunicação dialógica, autonomia, pertencimento territorial.

\section{Retomando o Conceito de Gestão SOCIAL}

A gestão social nasce em meados dos anos 90, em resposta aos fenômenos socioeconômicos vivenciados nesse período. Nessa década, segundo Cançado (2014), é criado o Programa de Estudos em Gestão Social Brasileira de Administração Pública e de Empresas da Fundação Getúlio Vagas (PEGS/EBAPE/FGV), coordenado pelo professor Fernando Tenório, que dá início aos debates sobre gestão social no Brasil.

Ultrapassando a gestão de políticas públicas, a gestão social, em construção, amplia seu campo e passa a atuar desenvolvendo ações caracterizadas pela "[...] tomada de decisão coletiva, sem coerção, baseada na inteligibilidade e transparência, buscando o entendimento e não a negociação." (CANÇADO, 2014, p. 82). O direito à fala é de todos, as decisões são tomadas de forma conjunta, porém isso não significar dizer que interesses divergentes não podem surgir, mas que, através de um consenso sem repressões, chegar-se-á a uma decisão cujo norte deve ser a primazia do melhor para todos, com compromisso social e ambiental. 
O termo Gestão Social tem sido objeto de estudo e prática associado às políticas sociais e ambientais, às organizações do terceiro setor, ao combate à pobreza, ao desenvolvimento territorial e à possibilidade de uma gestão democrática, participativa, quer na formulação de políticas públicas quer naquelas relações de caráter produtivo. Ademais o adjetivo social qualificando o substantivo gestão é percebido como espaço privilegiado de relações sociais onde todos têm o direito a fala, sem nenhum tipo de coação (SILVA JÚNIOR 2008).

Subvertendo a ordem da gestão tradicional, que visa o lucro como meta, a finalidade econômica não está em primeiro plano nessa gestão de demandas e necessidades sociais, realizada pela própria sociedade, em uma esfera pública de ação, na qual

[...] o econômico aparece apenas como meio para a realização dos fins sociais, que podem definir-se também em termos culturais (de promoção, resgate ou afirmação identitária, etc.), políticos (no plano de uma luta por direitos, etc.) ou ecológicos (em termos de preservação e educação ambiental). (FRANÇA FILHO, 2008, p. 32)

Essa forma de gestão constitui-se em um

[...] modo de orientação para uma ação organizacional, que do ponto de vista de sua racionalidade pretende subordinar as lógicas instrumentais a outras lógicas mais sociais, políticas, culturais ou ecológicas. (FRANÇA FILHO, 2008, p. 27)

Inovando por meio da participação, dialogicidade e horizontalidade das relações, a proposta é (re) significar ações coletivas para gerar transformações sociais, colocando os atores sociais como responsáveis autônomos e capazes de modificar a realidade em que se encontram, visando alcançar benefícios coletivos. Sua atuação não é estatal; a sociedade é a protagonista, atuando para perceber, discutir e buscar soluções para as problemáticas vivenciadas no cotidiano, sendo necessário que os afetados pelas decisões tomadas participem como sujeitos ativos desse processo.

Esse tipo de gestão pauta-se pelos princípios de cidadania deliberativa, que são, de acordo com Tenório (2008), inclusão, pluralismo, igualdade participativa, autonomia e bem comum; podendo ocorrer tanto nos sistemas público e privado, como, principalmente, em organizações não governamentais, onde o processo decisório deve envolver todos como protagonistas, sem hierarquização.

Cançado (2014) explica que essa maneira de gestão baseia-se no Interesse Bem Compreendido, conceito apresentado por Tocqueville segundo o qual o bem-estar coletivo é pré-condição para o bem-estar individual; acontece na Esfera Pública, espaço onde indivíduos privados encontram-se para discutir acerca de assuntos públicos; e tem como objetivo a Emancipação para alcançar a autonomia dos sujeitos, em uma perspectiva dialógica negativa adorniana, sem pretensões de síntese.

A mobilização para o desenvolvimento das ações sociais parte da comunicação, que pressupõe o encontro dos sujeitos em um espaço público para tratar de interesse coletivo, identificando quais são as demandas presentes e buscando, elaborando e executando ações para alcanças os objetivos desejados. Chegando ao resultado ou quando o assunto já não faz mais parte do interesse coletivo, novos levantamentos e ações surgem, mostrando que a gestão social está em produção constante.

França Filho (2008) e Cançado, Pereira e Tenório (2013) refletem que a gestão social tem conquistado uma grande visibilidade tanto no meio acadêmico como no espaço midiático, o que acaba contribuindo para a banalização do termo, englobando tudo o que não é gestão tradicional como gestão social. No entanto, desenvolver a gestão social não é simples, muitos são os obstáculos encontrados. É preciso ter os preceitos teóricos e éticos apresentados no decorrer deste tópico para embasar a prática. Partindo dessas questões, reflete-se como é possível aplicar os princípios da gestão social à juventude. Nesse sentido, serão apresentados, no próximo tópico, uma breve discussão sobre esse conceito e as possíveis articulações.

\section{Juventude e Processos Participativos}

As discussões atuais sobre juventude buscam verificar aspectos singulares dessa faixa geracional, como o entendimento da duração dessa fase e das características que a compõe. Segundo Anjo e Nascimento (2012, p. 6). 
Discutir sobre juventude exige uma compreensão das concepções recorrentes a ela transmitida de forma geral pela sociedade. Estas concepções apresentam a juventude como um momento de transição para a vida adulta que corresponde a uma fase de preparação para a integração na vida social através do aprendizado da cultura.

Dayrell (2003) considera que a juventude é, ao mesmo tempo, uma condição social e um tipo de representação. Isso quer dizer que cada sociedade, em seu contexto histórico, tem uma representação diferente do ser jovem; portanto, não se pode restringir juventude a uma faixa etária. Na atualidade, a representação sobre a juventude ainda é associada a uma fase geracional permeada por crises de identidade e comportamentos inconsequentes.

O autor supracitado afirma que há uma série de imagens associadas ao jovem difundidas no cotidiano, sendo que, dentre elas, "Uma das mais arraigadas é a juventude vista na sua condição de transitoriedade, na qual o jovem é um 'vir a ser', tendo no futuro, na passagem para a vida adulta, o sentido de suas ações no presente." (DAYRELL, 2003, p. 156).

Nesse sentido, até mesmo a educação formal do jovem é voltada para o que ele pode vir a ser como profissional apto ao mercado de trabalho. $\mathrm{O}$ mesmo autor afirma que uma segunda forma de ver o jovem é derivada da década de 60 , quando a indústria cultural florescia e o mercado se voltava para essa classe. Com isso, a juventude foi associada a um tempo de "[...] liberdade, de prazer, de expressão de comportamento exóticos." (DAYRELL, 2003, p. 156). Seria também uma época marcada por uma experimentação, momento para ensaio e erro, em que a irresponsabilidade e a ação não pensada são inerentes ao ser. A juventude também pode ser considerada uma fase difícil, de baixa autoestima e conflitos de personalidade, além de afastamento da família; quando o núcleo familiar, a escola e o trabalho perdem a função de centro de orientações e valores.

Vargas (2004) reflete que, para esse público, é necessário pensar em estratégias de enfrentamento dos estereótipos supracitados, para desnaturalizar a figura do jovem como um ser imaturo e pensá-lo como um ator social emergente em sua localidade, com potencial para transformar sua realidade e que pode contribuir para a superação das situações de vulnerabilidade vivenciadas em seu cotidiano.

Dessa discussão, entendemos a juventude como parte de um processo mais amplo de constituição de sujeitos, mas que tem especificidades que marcam a vida de cada um. A juventude constitui um momento determinado, mas não se reduz a uma passagem; ela assume uma importância em si mesma. Todo esse processo é influenciado pelo meio social concreto no qual se desenvolve e pela qualidade da troca que esta proporciona (DAYRELL, 2007, p. 158).

Olhando para o contexto escolar em que os jovens estão inseridos, observamos uma ênfase na competitividade ainda mais acirrada, devido à proximidade dos processos seletivos para ingresso no ensino superior ou da inserção no mercado de trabalho. Segundo Leher (2010), a trajetória das práticas educativas é permeada por interesses voltados a disciplinarização e ao aumento da produtividade, disponibilizando de forma restrita o acesso à educação e a embasando em um modelo que não leva em consideração as particularidades de determinados povos, se configurando como uma prática verticalizante e desprovida de espaços de reflexão: "A Educação é parte da estratégia política e por isso, historicamente, os setores dominantes têm empreendido esforços para caracterizá-la e aprisioná-la como um campo guiado por razões utilitaristas." (LEHER, 2010, p. 19).

É preciso observar, portanto, que os jovens enfrentam cotidianamente desafios, por exemplo, centralização de poder na figura do professor e rivalidade entre os colegas, o que evidencia o ethos do capital, afirmando a importância da individualização, onde cada um é único responsável pelo seu sucesso ou fracasso, pautado na ética do liberalismo, em que os vínculos entre as pessoas são incipientes, dificultando o alcance de projetos coletivos. Isso acontece a partir de um conjunto de códigos, valores, ideais e condutas apresentados por esse ethos que define padrões e referencia os sujeitos, de modo a levá-los a compreender "quem são".

Essas regras culturais são aprendidas pelo processo de socialização, disseminando componentes ideológicos pelo uso da fala. Por ideologia, entendemos ideias e crenças destinadas a convencer da sua "veracidade", mas que estão a serviço de interesses dominantes. Por meio da linguagem, que traz significado aos fenôme- 
nos sociais, aprendemos uma cultura de dominação. Esse não é um processo linear, mas sofre modificações históricas. Nesse sentido, os códigos morais e atos de condutas moldam a nossa subjetividade.

Nesse sentido, as escolas com técnicas pedagógicas tradicionais parecem reforçar uma situação de dominação, que impossibilita o jovem refletir os conteúdos vistos em sala de aula com aspectos intrínsecos a sua realidade. "Eis aí a concepção 'bancária' da educação, em que a única margem de ação, que se oferece aos educandos é a de receberem os depósitos, guardá-los e arquivá-los." (FREIRE, 2005b, p. 66). O jovem é visto como mero depósito de informações técnicas necessárias para a utilização em suas atividades rotineiras.

Partindo desse pressuposto, acredita-se que, assim como foi possível fomentar uma juventude alheia às questões locais coletivas, é também possível aprender novos referenciais preconizados pela Gestão Social no espaço escolar. Para isso é preciso um posicionamento ético, capaz de romper com os jogos de poder, apontando enfim para uma estética da existência, definida como prática emancipatória. Segundo Cançado, Pereira e Tenório (2013), emancipação significa sair da tutela de alguém, uma capacidade interna para dar-se a si mesmo sua própria lei ou regra, uma ruptura com o processo de manipulação, a autopercepção como sujeito político, sendo esse o principal objetivo da Gestão Social. Alcançar o nível de participação política/ ética proposta parece-nos carecer de um investimento educacional para construção de um novo ethos, que supere a lógica da educação tradicional adaptada ao processo tecnicista e competitivo, voltado a assegurar aos alunos saberes que garantem produtividade $e$ sucesso no mercado.

Essa discussão de mudança do ethos nos remonta à educação popular iniciada na década de 1950 por Paulo Freire. Para o autor, uma forma de emancipação, das forças dominantes e opressoras, poderá acontecer por práticas educativas reflexivas, onde os oprimidos podem visualizar de forma crítica sua realidade, impulsionando a tomada de consciência destes e os estimulando ao engajamento em movimentos que prezem pela libertação do julgo dos opressores. A libertação autêntica não é algo pronto a ser doado, mas a ser construída, a humanização é um processo, a práxis é a metodologia, "[...] que implica a ação e reflexão dos homens sobre o mundo para transformá-lo [...]" (FREIRE, 2005b, p. 77), assim na educação problematizadora a aprendizagem é sempre de todos os sujeitos.

"Libertação a que não chegarão pelo acaso, mas pela práxis de sua busca, pelo conhecimento e reconhecimento da necessidade de lutar por ela." (FREIRE, 2005b, p. 34). Diferente das práticas usuais, a práxis é entendida por Freire (2005a) como uma ação que promove a reflexão e a partir desta inquieta o sujeito buscar transforma sua realidade, fugindo do modelo bancário, onde os alunos são meros depósitos de informações. A práxis educativa visa que o aluno não apenas absorva os conteúdos estudados, mas que os utilizem em problemas cotidianos, para questionar aspectos de sua trajetória.

Para sair da posição de oprimido, o processo de libertação dá-se através do descobrimento da realidade opressora, para então poder agir, como explica Freire (2005b, p. 46):

\section{A pedagogia do oprimido, como pedagogia humanista e libertadora, terá dois momentos distintos. O primeiro, em que os oprimidos vão desvelando o mundo da opressão $e$ vão comprometendo-se, na práxis, com sua trans- formação; o segundo, em que, transformada a realidade opressora, esta pedagogia deixa de ser do oprimido e passa a ser a pedagogia dos homens em processo de permanente libertação.}

Essa proposição de ruptura ideológica pela fala nos leva à discussão de Habermas (1984) sobre ação estratégica X ação comunicativa. No primeiro modelo, a fala é utilizada como instrumento de manipulação dos sujeitos com fins específicos. No segundo modelo, a fala seria utilizada numa perspectiva emancipatória, segundo a qual todos teriam acesso equitativo a bens e serviços. Para Harbermans (1987), a fala é o princípio que produz liberdade, quando as pessoas poderiam ser livres para pensar e agir sobre sua realidade, aproximando-se da prática da cidadania em seu conceito real.

Tal prática de cidadania é um desafio permanente, afinal, os sujeitos foram ensinados a agir como indivíduos, ou seja, separados, isolados, destinados a tratar com rivalidade os que estão próximo, quebrando o princípio do bem-comum presente na res-publica, prevalecendo os interesses individuais, ou res-privacta. Portanto, dificulta a prática da cidadania, que pressu- 
põe relação entre os sujeitos, ou seja, mutualidade, sentimento de pertencimento (TENÓRIO, 2007).

O conceito de cidadania baseado na noção de bem comum, discutido por Tenório (2007), dialoga com as ideias da ética/estética da existência de Foucault (2010). Isso implica que os sujeitos se sintam livres para decidir sobre sua vida, referenciados no bem coletivo. A dimensão ética da existência problematizada por Foucault (2010) refere-se à ideia de que a vida deve ser avaliada a partir de um viés artístico, tornando-se bela aos olhos de quem a vê. Para essa discussão, ele toma duas dimensões: práticas reflexivas de cada um com ele mesmo e a relação com os outros.

A primeira dimensão afirma que a ética implica num "cuidado de si", um termo grego que seguiu toda filosofia antiga até o limiar do cristianismo. "O cuidado de si é ocupado pelo imperativo do conhece-te a ti mesmo [...]" (FOUCAULT, 2010, p. 228); portanto, é o momento em que o sujeito, através da reflexão sobre o próprio pensamento, alcança o primeiro despertar sobre a sua existência. Essa reflexão incita as pessoas ao movimento, ou seja, às ações que trazem mudanças em relação a si mesmas, ao mundo e ao outro. A relação de mutualidade entre o "cuidado de si" e "conhece-te a ti mesmo" nos remonta mais uma vez à matriz libertária de Paulo Freire (2005a), que nos apresentava as possibilidades de mudança a partir do "olhar para dentro" da comunidade, conhecendo as potencialidades locais para, então, pensar as estratégias de ação política.

O "cuidado de si" tem um fim político, "[...] ocupar-se de si mesmo parte do poder de ocupar-se com os outros" (FOUCAULT, 2010, p. 157). O fato de ocupar-se com os outros voltaria em proveito próprio, pois, na medida em que cuido dos males da minha comunidade, cuido dos meus próprios problemas. É uma relação de reciprocidade, ou circular, composta pelo conhecimento de si, conhecimento da verdade, cuidado de si. A reflexividade presente no cuidado de si pode favorecer a autonomia dos sujeitos, capazes de assumir funções antes exercidas pelos outros (FOUCAULT, 2010).

Nesse sentido, parece haver uma tendência a um discurso social sobre "o jovem irresponsável" em detrimento do lugar do jovem político. Apesar dos avanços obtidos na reconstrução desse discurso social sobre o jovem, haja vista a criação do Estatuto da Juventude, é perceptível que os jovens não têm ocupado o lugar de interlocutor na criação das políticas públicas, que são elaboradas por adultos a partir das suas perspectivas sobre o que seriam as necessidades da juventude. Vargas (2004) afirma que se faz necessário ampliar o conceito de juventude, abrir espaços para a participação juvenil nos processos de tomada de decisão e criar políticas públicas voltadas para essas pessoas.

\section{Procedimentos Metodológicos}

Este estudo trata-se de uma pesquisa descritiva de caráter qualitativo. Segundo Gil (2008), tal modelo objetiva trazer de forma clara e precisa as características do público elencado para o estudo e também possibilita investigar em profundidade como se relacionam os indicativos que aparecem em determinado estudo. O método escolhido para estruturar esta pesquisa, crítico-dialético, compreende o homem como um ser social e histórico, capaz de agir sobre sua realidade e transformar seu contexto, com potencial para identificar seu papel na sociedade a partir de uma postura política de práticas revolucionárias. Portanto, parte de um modelo diacrônico, inserindo o tempo como fator primordial para compreender o objeto. Desse modo, a historicidade é tomada como principal fator para investigação educativa, com a finalidade de desvendar os conflitos de interpretação e interesse diversos (GAMBOA, 2012).

Durante o período de vigência do projeto, a coleta de dados foi feita a partir da realização de grupos focais, instrumento definido por Ressel et al. (2008, p. 780) como "[...] grupos de discussão que dialogam sobre um tema em particular, ao receberem estímulos apropriados para o debate". Tal instrumento fornece informações valiosas sobre aspectos intrínsecos à interação grupal e também auxilia a integrar os participantes da pesquisa, envolvendo-os e tornando o ambiente agradável a todos. Os grupos foram realizados no final de cada atividade feita com os jovens, com a duração aproximada de uma hora e meia, contendo perguntas voltadas à avaliação do processo concebido naquele dia. As informações foram coletadas nos grupos por meio do preenchimento de fichas de avaliação pelos bolsistas do projeto. 
A coleta dos dados foi realizada durante o ano 2013, na escola de ensino médio Centro de Apoio Integral à Criança e ao Adolescente Dom Antônio Campelo de Aragão (CAIC) e na Escola Estadual Antônio Conserva Feitosa, ambas localizadas na cidade de Juazeiro do Norte. O público-alvo foi composto por jovens do sexo masculino e feminino, entre 14 e 19 anos, matriculados regularmente nas instituições supracitadas e que aderiram ao projeto. Para ser incluído na pesquisa, o participante deveria estar matriculado $e$ frequentar as ações do projeto. A escolha desse critério deu-se a partir da necessidade de se fazer um acompanhamento contínuo do desenvolvimento das habilidades sociais nos membros do grupo e também para buscar entender qual o impacto do projeto na vida dos seus participantes. Como critério de exclusão, estabeleceu-se o fato de o aluno não pertencer ao ensino médio ou não frequentar as ações do projeto por pelo menos cinco encontros.

Para a realização do tratamento dos dados coletados, foi escolhida a técnica da análise do discurso, descrita por Rocha e Deusdara (2005, p. 308) como um método que "[...] propõe o entendimento de um plano discursivo que articula linguagem e sociedade, entremeadas pelo contexto ideológico". Tal escolha se justifica pela necessidade de se entender as particularidades dos integrantes do projeto e de como ocorre a interação entre eles e as temáticas abordadas durante a vigência do projeto.

\subsection{Relato de Prática}

O Projeto Gestão Social nas Escolas adentra no ambiente escolar com o intuito de articular os atores sociais presentes nesse espaço, estimulando a criação de estratégias locais para intervir em situações-problema. As ações foram realizadas sob a perspectiva da Matriz Libertária de Freire; uma ruptura com o paradigma da educação tradicional, de modo que os sujeitos possam atuar no diagnóstico dos problemas e buscar soluções, sendo vistos como agentes transformadores, desenvolvendo habilidades e atitudes através de uma conduta ética, condizente com o exercício da cidadania (FREIRE, 2005a).

Para esse autor, a valorização do saber popular e o trabalho contextualizado à realidade de cada espaço faz com que os sujeitos sintam-se atraídos a pensar em como resolver os problemas que atingem seu dia a dia, provocando a vontade de participar desse momento de transformação vivenciado em sua comunidade.

A pedagogia da libertação é um modelo que estimula a participação popular, horizontalizando as relações e destituindo a centralização do conhecimento por uma figura de suposto saber. Esse modelo rompe com as práticas disseminadas pelo protótipo utilizado nas instituições adeptas da educação tradicional, pois traz aos alunos a possibilidade de participar de forma ativa das atividades educacionais e de se ver como agente transformador do espaço escolar (FREIRE, 2005a).

Nesse sentido, o projeto Gestão Social nas Escolas foi dividido em três etapas. A primeira foi dedicada ao desenvolvimento das habilidades sociais dos jovens, trabalhando também o fortalecimento dos vínculos já existentes e o pertencimento ao território. O propósito dessa fase é fazer com que eles olhem para dentro da comunidade; é despertar nos adolescentes uma reflexão sobre os problemas que existem em seu lugar, de modo a buscar formas de solucioná-los cooperativamente. Logo em seguida, eles deveriam olhar para dentro de si mesmos, conhecer talentos e potencialidades que possuem, para, só então, olhar para o outro, identificando as semelhanças que podem gerar conexões, laços sociais. Esse movimento de olhar para essas três dimensões - Sujeito, o Outro e a Comunidade - poderá propiciar o espaço esperado para a construção de uma identidade que favoreça a realização de projetos coletivos.

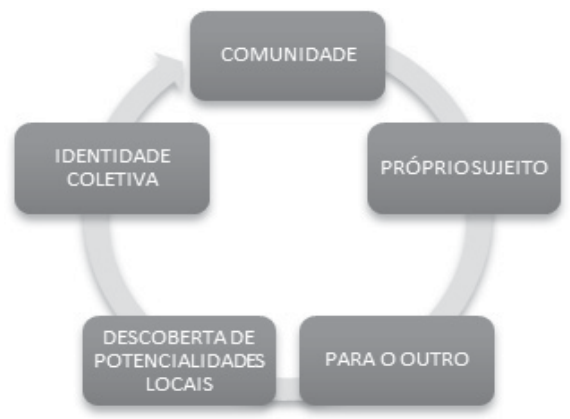

Figura 1: Fase 1 - $\mathrm{O}$ olhar para dentro: comunidade, sujeito, outro

Fonte: Elaborada pelas autoras deste artigo

Essa primeira etapa tem como objetivo apresentar aos jovens possibilidades de mudança a partir do "olhar para dentro" da comunidade, conhecendo as 
potencialidades locais para, então, pensar as estratégias de ação política.

O esforço racional para que os jovens "olhem para dentro" refere-se à observação de que, em geral, as pessoas encontram-se num espaço físico, mas estão desagregadas, desconectadas. A partir de intervenções específicas, é possível reestabelecer os laços sociais. Os estudos sobre território demonstram algumas das estratégias para esse fim. O território se configura como um espaço dominado por um grupo de pessoas, onde valores diversos são compartilhados. Nele também há um poder que proporciona um reconhecimento de uma identidade territorial, afinal, experiências partilhadas, triunfos e perdas produzem sentidos e conectam as pessoas.

A identidade territorial está fundamentada na cultura. A cultura une o grupo e a identidade o diferencia dos outros. Portanto, o conceito de identidade tornou-se um caminho de ordem política para atuar no território, ao enfatizar a unidade e não o isolamento das pessoas. As ações no território, segundo Fischer (1996), podem reestabelecer os laços sociais perdidos, refazendo a rede local, melhorando a interação entre os sujeitos, que compartilharão interesses comuns $e$ resolverão problemas a partir da ajuda mútua. Essa pode ser a força propulsora para enfrentar as incertezas das crises.

A retomada da identidade local valoriza aspectos endógenos fundamentais, a partir da reconstrução histórica da ocupação da região e da constituição dos grupos. A ideia é fortalecer os laços sociais, tornar sujeitos em relação, ou seja, implicados em uma mutualidade, em um sentimento de pertencimento. Agora não se fala em apenas um eu, mas em nós, com objetivo comum.

$\mathrm{Na}$ etapa seguinte, apenas os alunos que se identificaram com as ações ocorridas no processo de sensibilização continuaram no projeto, por meio da adesão voluntária. Para Espósito (2010), o jovem deve ter a liberdade de escolher como participar, posicionar-se frente às ações para mudança do contexto social, quer seja como um ator social protagonista quer seja como um mero espectador.

Cançado, Pereira e Tenório (2013, p. 154) consideram a participação como "[...] um processo de capacitação e conscientização para o desenvolvimento da cidadania". Ao participar de algo, o sujeito imprime no mundo sua marca, trazendo reflexões e ações que visam melhorar ou modificar aspectos relevantes apresentados no seu cotidiano. Isso só é possível se houver implicação do sujeito naquilo a que ele se propõe.

Após esse processo de adesão voluntária, os estudantes foram estimulados a construir planos de intervenção para os problemas levantados na fase anterior, levando em consideração as habilidades e capacidades mapeadas nessa etapa. A estrutura dos planos era composta de objetivos, justificativas, metas, atividade e orçamento. Todo o processo de construção aconteceu a partir da utilização de recursos lúdicos, como jogos cooperativos, que tornaram a atividade um processo divertido e dinâmico. Nessa segunda fase, era esperado o surgimento de um grupo - o que implica em pessoas vinculadas por um objetivo comum. Desse modo, poderiam utilizar as ferramentas de planejamento e intervenção para intervir no desafio comum.

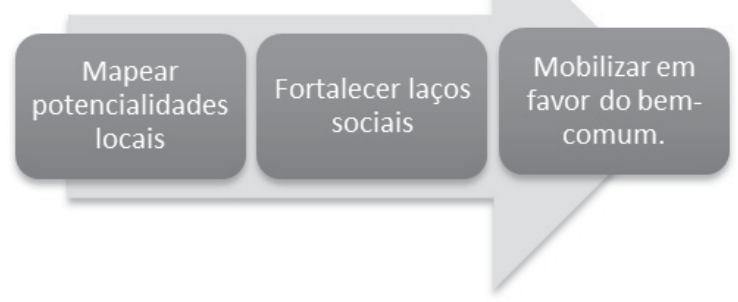

Figura 2: Fase 2 - Do pensar ao fazer: a construção de projetos sociais.

Fonte: Elaborada pelas autoras deste artigo

O Projeto Gestão Social nas Escolas buscou estimular o protagonismo juvenil a partir de estratégias que proporcionavam ferramentas importantes para os processos de tomada de decisão e conscientização dos jovens sobre sua realidade, tanto na escola como na comunidade, instigando-os a pensar em soluções para melhorá-las.

Na última fase do PGSE, os planos de ação aprimorados na etapa anterior foram executados. A maior parte deles trabalhava de forma pontual questões relacionadas à violência escolar, violência urbana e preservação do meio ambiente. Dessa forma, surgiram os três projetos que participaram de um processo de incubação mediante o apoio da Incubadora Tecnológica de Empreendimentos Populares e Solidários (ITEPS), também da Universidade Federal do Cariri (UFCA). Nesse processo, os jovens participaram de oficinas voltadas para temas relacionados ao cooperativismo, 
ao associativismo e à autogestão. É visível, nessa etapa, o amadurecimento pessoal e grupal dos jovens envolvidos, assim como o fortalecimento dos vínculos grupais e com os parceiros do projeto.

\section{Resultados e Discussões}

Durante o período de aplicação do projeto foi observado o aparecimento de alguns potenciais relevantes para o processo de protagonismo juvenil. Habilidades voltadas aos princípios da Gestão Social, como o diálogo problematizador, a participação ativa, a cidadania e a autonomia. As falas dos jovens utilizadas neste tópico foram coletadas a partir de uma atividade de avaliação. Quando aplicamos a técnica no grupo focal, estavam presentes dezesseis jovens participantes do projeto. Partimos de uma questão mobilizadora: "Quais mudanças vocês perceberam no cotidiano após as ações do projeto?".

Por uma hora e meia, os jovens falaram livremente sobre diversos elementos, o que foi devidamente registrado pelo uso de gravador e por anotações. Logo em seguida, buscamos identificar, a partir da análise do discurso, quais habilidades foram desenvolvidas durante o PGSE. Dividimos a análise dos dados em três categorias principais: Participação; Dialogicidade, Entendimento Mútuo; Processos de Autonomia, Emancipação.

\subsection{Participação}

A primeira habilidade apreendida nos discursos refere-se à mudança de postura dos jovens, saindo da situação de timidez para participação nas atividades propostas pela equipe, como se observa nesta fala: "Eu era muito tímido, nem falava. Achavam que iam rir de mim, mas, com o tempo, consegui e, hoje, já fui instrutor de oficinas de reciclagem. Eles me chamaram de professor" (Jovem PGSE).

Também foi observado que as ações ocorridas durante o processo eram pautas na lógica da práxis transformadora, da ação-reflexão. Assim, os temas trabalhados na escola foram levados para outras esferas da vida dos alunos: "Percebi que eu tinha que ser persistente pra alcançar objetivos. Aprendi a falar em público, era meganervosa, e o projeto me ajudou muito nisso. Agora participo das feiras de ciências na boa" (Jovem PGSE). A superação da timidez e ampliação da participação em outros espaços também são identificadas na fala abaixo:

Eu sou tímido, mas as formações do projeto me ajudaram. Na escola mudou, eu não perguntava aos professores, ficava com as perguntas dentro de mim, quando chegava em casa tentava estudar só para tirar as dúvidas. Mas agora é diferente, sou mais comunicativo. Antes era assim: "fala, fala...". Hoje eles não precisam mais pedir. (Jovem PGSE).

Freire (2005b) retrata a dialogicidade como algo primordial para inserir as pessoas nesse processo de reflexão, pois, ao dialogar, o ouvinte não deve se configurar como um mero depósito de informações, e sim como um sujeito que, ao assimilar tal conteúdo, aproxima-o de sua realidade e faz inferências, buscando transformar o espaço onde está inserido.

A partir das atividades desenvolvidas no projeto, os alunos verbalizam a perda da timidez e do medo de se expressar nas ações da escola como é apontado novamente neste discurso: "(Eu) era mais calada e buscava ouvir mais; hoje consigo falar e dar opiniões, consigo até debater ideias" (jovem PGSE).

\subsection{Dialogicidade, Entendimento Mútuo}

Outra habilidade identificada no processo foi a capacidade de entendimento mútuo em favor do bem comum. Essa habilidade é posta em questão cotidianamente, devido à valorização do individualismo e da competitividade, em função das quais as pessoas colocam seus interesses individuais acima dos interesses da coletividade, o que gera diversas situações de conflitos. Essa capacidade de entendimento mútuo em favor do bem comum faz parte do conceito de cidadania deliberativa, que, segundo Tenório e colaboradores, trata-se de:

[...] uma cidadania ativa, relacionada com a presença constante da sociedade civil nas discussões na esfera pública, interagindo com a economia e com o Estado. Nesse sentido, a esfera pública deve identificar, compreender, problematizar e propor soluções aos problemas da sociedade, a ponto de estes serem assumidos como políticas públicas e executados pelo aparato administrativo de governo. (TENÓRIO et al., 2010. p. 4) 
O mesmo autor afirma que a prática desse modelo ocorre quando há espaço para o diálogo, onde são emitidas opiniões e tomadas decisões sobre determinado assunto a partir do entendimento mútuo entre os envolvidos.

$\mathrm{O}$ ato de agir em favor do bem comum é desafiador, pois, imersos em numa cultura da competitividade, os sujeitos sentem dificuldades em assimilar um trabalho nessa perspectiva, haja vista terem sido ensinados, desde pequenos, a ver aquele que anda ao seu lado como seu adversário. Segundo Paul Singer (2002, p. 103): "A competição tem como fim lógico apontar um vencedor $e$, para que haja incentivos para competir, é preciso que o vencedor seja devidamente recompensado e os vencidos punidos".

Logo, os interesses da esfera privada são postos em evidência, em detrimento das necessidades observadas na esfera pública e nas atividades inerentes a esta. Isso ocasiona entraves no exercício de práticas cidadãs, pois tais práticas preconizam que as relações interpessoais se configurem como relações de apoio mútuo, onde prevaleça o pertencimento a determinado lugar ou grupo (TENÓRIO, 2007).

Logo que o projeto entrou em nossas vidas, eu não sabia aceitar a opinião dos outros; eu dizia: não é isso não, e acabou. É do jeito que eu quero. Com o passar do tempo, eu percebi que é besteira: sempre vai ter opinião diferente, gente dizendo não, outro sim. Hoje, eu já aceito. Se tá bom assim pro grupo todo, então vai ficar pra mim. (Jovem PGSE)

As pessoas são diferentes. Aprendi a ouvir a opinião dos outros e esperar; depois chega a minha vez. (Jovem PGSE)

Segundo Tenório (2007), a prática da cidadania pode ocorrer pela reativação da esfera pública. Onde há um espaço de comunicação adequado, as decisões são tomadas e as opiniões são conversadas e sintetizadas a partir do entendimento mútuo. Novamente observamos esse elemento na fala abaixo:

Eu aprendi a saber ouvir opinião diferente. Eu sempre falei demais, tomei a frente das coisas. Com o projeto, aprendi a esperar a minha vez de falar; eu me controlo e tento respeitar o espaço do outro (Jovem PGSE).
O compartilhamento de opiniões feitas de forma horizontal e participativa fez com que os jovens fortalecessem os vínculos já existentes na sala de aula e também com que eles se reconhecessem como parte integrante da turma, como é perceptível nesta fala: "É importante, porque o PGSE nos mostra as dificuldades que poderemos enfrentar, mas também nos mostra que trabalhar em grupo pode facilitar nossos desafios" (Jovem PGSE).

Essa categoria acima descrita está ainda relacionada ao Interesse Bem Compreendido apresentado por Cançado, Pereira e Tenório (2013). Segundo o autor, o IBC baseia-se na premissa de que o bem-estar coletivo é uma precondição para o bem-estar individual; uma relação de mutualidade capaz de estruturar uma solidariedade social, apontando, enfim, para uma coesão social, elemento necessário para alcançar a sustentabilidade dos projetos coletivos.

\subsection{Processos de Autonomia, Emancipação}

A gestão social possibilita aos sujeitos a participação igualitária no processo de tomada de decisão, partindo do princípio de que o ato de falar tem caráter emancipatório, por meio do respeito aos princípios éticos e da negociação de conflitos aparentes. A gestão social tem como grande desafio a criação de estratégias que estimulem a participação e o desenvolvimento da autonomia dos sujeitos (ALENCAR; GRANGEIRO, 2012).

O projeto é uma responsabilidade muito grande,
porque ele entrou nas nossas vidas através de
vocês, mas somos nós que estamos construindo
o projeto. Somos nós que fazemos as ações. Não
precisa ninguém dizer: "óh, faz isso". "Eu já vou
lá e faço" (Jovem PGSE).

Para atingir esses objetivos, primeiramente é preciso estimular os jovens, a partir de práticas oriundas da educação dialógica. Para se chegar a isso, o gestor social pode recorrer às técnicas de metodologia participativa - por exemplo, os jogos cooperativos e as rodas de conversa, onde educando e educador passam a ter uma relação horizontal - e estimular os jovens a participar das ações:

Durante o projeto nós aprendemos a ter organização. Escolher o tema a ser retratado. Escutar 
opiniões de outros membros. Colocar em prática a apresentação. Ouvir mais as opiniões. Ter calma. Saber decidir e ouvir. Trabalhar em grupos (Jovem PGSE).

A fala anterior vai ao encontro das práticas da educação popular Freiriana, que provê aos sujeitos uma nova forma de ler o mundo, por meio da qual eles se conectam para buscar soluções para os problemas locais e conseguem se ver como agentes da transformação dessa realidade.

A capacidade de dialogar é necessária, pois permite que os componentes do grupo cheguem a um consenso sobre como resolver seus conflitos, produzindo soluções em favor do bem comum. Kisil (2005 apud ALENCAR; GRANGEIRO, 2012) relata que a habilidade da fala adequada é

[...] o primeiro passo para o amadurecimento do grupo, que passa a ter a oportunidade de pensar os problemas e soluções para questões locais, criando uma identidade comum, fora da lógica da competição, mas sim na da cooperação. (ALENCAR; GRANGEIRO, 2012, p. 52)

Por fim, observa-se, na fala a seguir, que as ações do Projeto Gestão Social nas Escolas fomentaram, em alguns jovens, um posicionamento mais seguro ou, podemos dizer, fomentaram sujeitos políticos aptos a intervir nos desafios cotidianos.

Tenho aprendido a ser persistente. Antes do projeto eu não era persistente. Antes, se eu tivesse fazendo alguma coisa e alguém dissesse que não estava bom, na mesma hora eu parava e pronto, Com o projeto, me senti mais seguro, mais persistente; eu consigo falar minha opinião (Jovem PGSE)

Essas relações dialógicas capazes de serem desenvolvidas em práticas da Gestão Social podem gerar um novo ethos, que se configura como "um lugar de sentido, princípios, normas e hábitos", superando o ethos do capital e estimulando práxis emancipatórias. No Projeto Gestão Social nas Escolas, as vivências realizadas foram pautadas por conceitos de emancipação e autonomia e trouxeram ao público-alvo assistido ferramentas para o fomento dessas habilidades.

\section{Considerações Finais}

Essa experiência demonstrou a importância de um investimento mais assertivo na juventude, a partir de espaços prático-reflexivos para uma ruptura no ethos do capital pautado na ética liberal. O projeto auxiliou os alunos a desenvolver habilidades importantes, como a autonomia e as capacidades de gerenciar conflitos e enxergar o seu pertencimento à comunidade e desenvolver a cidadania sob o viés da ética da solidariedade, modelo pautado na cooperação e na transformação da realidade em que os sujeitos se encontram.

Para se chegar ao resultado final, houve um conjunto de desafios a serem superados, como o grande número de alunos por turma, a timidez e a limitação temporal. Mas, com o passar do tempo, os jovens conseguiram superar esses desafios, principalmente no que diz respeito à timidez, pois estabeleceram relações de confiança entre eles e com os monitores do projeto e começaram a se implicar mais na construção das iniciativas de intervenção.

É importante destacar que, durante o projeto, os alunos conseguiram se enxergar como protagonistas no processo de transformação social de sua realidade, levando em consideração as potencialidades e fragilidades encontradas nessa realidade para construir estratégias de intervenção capazes de superar os problemas emergentes no cotidiano.

Os vínculos de confiança construídos durante o processo favoreceram o desenvolvimento da escuta $e$ das habilidades de entendimento mútuo, partindo do diálogo pautado no falar emancipatório e voltado à concretização de um desejo de transformação social partilhado por todos. A permanência em um grupo coeso torna o sujeito mais confiante, sem medo de expor seus posicionamentos para os outros. É notável que, nem sempre, os sujeitos estarão em concordância, mas - por meio de estratégias que demonstrem a necessidade de ouvir a opinião de todos e de pesar os prós e contras de cada uma - é possível chegar a um consenso.

No final do processo, é possível se chegar a uma solução em favor da coletividade, favorecendo a aprendizagem de uma prática emancipatória. Acreditamos que a aplicação deste projeto pôde ampliar os espaços participativos, a partir do desenvolvimento de habilidades por meio de atividades educativas fundadas na 
Gestão Social. Isso aconteceu inicialmente pela retomada dos vínculos de pertencimento territorial. Os jovens foram reconectados ao seu espaço físico e político.

Essa noção de pertencimento foi estimulada entre os jovens quando, nas etapas iniciais, fomentou-se um olhar para dentro da comunidade, retomando as experiências coletivas que deixaram registros pessoais. A reconexão com o espaço territorial pôde favorecer um sentimento de confiança nos espaços decisórios, proporcionando condições para o estabelecimento de um projeto coletivo e para, enfim, fazer com que esses atores sociais modifiquem a realidade da sua comunidade.

\section{REFERÊNCIAS}

ALMEIDA, Maria de Lourdes Pinto de. (Org.) Educação e movimentos sociais: novos olhares. 2. ed. Campinas: Alínea, 2010.

\section{ALENCAR, W. M.; GRANGEIRO, R. R. Os Desafios} da cidadania deliberativa: um estudo de caso sobre a participação dos jovens do Projeto Gestão Social nas Escolas. Revista Pensamento e Realidade, São Paulo, (USP), v. 27, n. 2, p. 41-55, 2012.

W. M.; VIEIRA, J. Q.; SILVA, A. K. Falar e

pertencer: desenvolvendo habilidades para a prática da gestão social. VIII ENAPEGS. Cachoeiras, 2014. Anais... Cachoeiras, 2014. Disponível em: <http://anaisenapegs. com.br/2014/dmdocuments/3032.pdf>. Acesso em: 20 out. 2014.

ANJOS, M. F.; NASCIMENTO, V. S. Processos de aprendizagem e desenvolvimento regional sustentável. VII Congresso Português de Sociologia. Porto, 2012.

Anais... Porto, 2012. Disponível em: < http://www.aps. pt/vii_congresso/papers/finais/PAP1033_ed.pdf $>$. Acesso em: 20 out. 2014.

CANÇADO, A. C.; PEREIRA, J. R.; TENÓRIO, F. J.

Gestão Social: epistemologia de um paradigma. Curitiba: CRV, 2013.

CANÇADO, Airton Cardoso. Gestão Social. In: BOULLOSA, Rosane de Freitas. (Org.). Dicionário para formação em gestão Social. Salvador: CIAGS/UFBA, 2014. p. $80-84$.
DAYRELL, J. O jovem como sujeito social. Rev. Bras.

Educ., Rio de Janeiro, n. 24, dez. 2003. Disponível em: <http://www.scielo.br/scielo.php?script=sci arttext\&pid=S1413-24782003000300004\&lng=en\&nrm =iso >. Acesso em: 10 nov. 2014.

FISCHER, Tânia. Análise de redes: uma contribuição aos estudos organizacionais. In: FISCHER, T.; RUBIM,

A. Gestão Contemporânea: cidades estratégicas e organizações locais. Rio de Janeiro: FGV, 1996.

FOUCAULT, M. A hermenêutica do sujeito: Curso dado no Collège de France (1981-1982). 3. ed. São Paulo: Martins Fontes, 2010.

FOUCAULT, M. Microfísica do poder. 3. ed. Rio de Janeiro: Graal, 1982.

FRANÇA FILHO, G. C. Definindo gestão social. In: SILVA JÚNIOR, J. T. et al. Gestão Social: práticas em debate, teorias em construção. Fortaleza: Imprensa Universitária, 2008.

FREIRE, P. Pedagogia da esperança: um reencontro com a pedagogia do oprimido. Rio de Janeiro: Paz e Terra, 2005a.

FREIRE, P. Pedagogia do oprimido. Rio de Janeiro: Paz e Terra, 2005b.

GAMBOA, S. Epistemologia e pesquisa em educação. Chapecó: Ed. Argos, 2012.

GIL, A. C. Métodos e técnicas da pesquisa social. São Paulo: Atlas, 2008.

HABERMAS, J. Mudança estrutural da esfera pública: investigações quanto a uma categoria da sociedade burguesa. Rio de Janeiro: Tempo Brasileiro, 1984.

\section{Teoría de la acción comunicativa I:}

racionalidad de la acción y racionalización social. Trad. de Manuel Jiménez Redondo. 4. ed. Madrid: Taurus, 1987.

\section{IBGE. INSTITUTO BRASILEIRO DE GEOGRAFIA} E ESTATÍSTICA. Cidades: dados demográficos da cidade de Juazeiro do Norte. Brasília, DF, 2012. Disponível em: <http://cidades.ibge.gov.br/xtras/perfil. php?codmun=230730I $>$. Acesso em: 15 ago. 2014. 
IPECE. INSTITUTO DE PESQUISA E ESTRATÉGIA ECONÔMICA DO CEARÁ. Perfil Básico Municipal

2013 - Juazeiro do Norte. IPECE: Fortaleza, 2013.

LEHER, Roberto. Educação Popular como estratégia política. In: ALMEIDA, Janize (Org.). Educação e movimentos sociais: novos olhares. São Paulo: Alínea, 2010.

PACHECO, Thiago da Silva. As duas faces da repressão: semelhanças e diferenças da polícia política durante o Estado Novo (1937-1945) e durante a Ditadura Militar (1964-1983). Revista de História Comparada, [S. l.], v. 4, n. 1, p. 126-139, dez. 2010.

RESSEL, Lúcia Beatriz et al. O uso do grupo focal em pesquisa qualitativa. Texto Contexto

Enferm., Florianópolis, v. 17, n. 4, Dec. 2008. Disponível em: <http://www.scielo.br/scielo.php?script=sci arttext\&pid =S0104-07072008000400021\&lng =en\&nrm =iso >. Acesso em: 25 fev. 2015.

ROCHA, Décio; DEUSDARA, Bruno. Análise de Conteúdo e Análise do Discurso: aproximações e afastamentos na (re)construção de uma trajetória. Alea, Rio de Janeiro, v. 7, n. 2, Dec. 2005.

Disponível em: <http://www.scielo.br/scielo. php?script $=$ sci_arttext\&pid $=$ S1517106X2005000200010 \&lng $=e n \& n r m=i s o>$. Acesso em: 25 fev. 2015.

SILVA JÚNIOR, J. T. et al. Gestão Social: práticas em debate, teorias em construção. Fortaleza: Imprensa Universitária, 2008.

SINGER, P. Introdução à economia solidária. São Paulo: Editora Fundação Perseu Abramo, 2002.

TENÓRIO, F. G. (Re)visitando o Conceito de Gestão Social. In: SILVA JÚNIOR, J. T. et al. (Org.). Gestão

Social: práticas em debate, teorias em construção. Juazeiro do Norte: Universidade Federal do Paraná, 2008. 1. v. p. 26-36.

TENÓRIO, F. G. et al. Da participação à cidadania deliberativa: os processos decisórios participativos na implementação das políticas públicas na Região do Noroeste Colonial Gaúcho. V ENCONTRO DE ADMINISTRAÇÃO PÚBLICA E GOVERNANÇA DA ANPAD. Vitória, 2010. Anais... Vitória, 2010. Disponível em: <http://ebape.fgv.br/sites/ebape.fgv.br/files/da participacao_a_cidadania.pdf>. Acesso em: 20 out. 2014.
. (Org.). Cidadania e desenvolvimento local.

Rio de Janeiro: FGV, 2007.

VARGAS, Gil Souza, C. Z. Juventude e contemporaneidade: possibilidades e limites. Última

Década, Santiago, CL, v. 12, n. 20, jun. 2004. Disponível em: <http://www.scielo.cl/scielo.php?script=sci_ arttext\&pid $=$ S0718-22362004000100003\&lng $=$ es\&nrm =iso $>$. Acesso em: 20 out. 2014. 